\section{What is already known on this topic}

The model of care for cancer patients that encompasses diagnosis, treatment, and palliative care is well developed

\section{What this study adds}

Patients with advanced cardiac failure have a different illness trajectory from those with inoperable lung cancer

Such patients and their carers have different concerns, a poorer understanding of the illness and prognosis, and less opportunity to address end of life issues than patients with lung cancer

Health, social, and palliative care services are less readily available to those with a non-cancer diagnosis

Care for patients with advanced cardiac failure should be proactive and designed to meet their specific needs

Western General Hospital, Edinburgh, St John's Hospital, Livingston, and Liberton Hospital, Edinburgh, for identifying patients. We especially thank Dr N Uren, Dr R Fergusson, Dr K Swarski, Dr P Cantley, Ms D Borthwick, and Ms M Smith for help with developing the recruitment strategy. We thank Dr M Dlugoleska of Lothian Health for help with study design. Contributors: See bmj.com
Funding: Chief Scientist Office of the Scottish Executive.

Competing interests: None declared.

1 Department of Health. National service framework for coronary heart disease. London: Department of Health, 2000.

2 Department of Health. The NHS cancer plan: a plan for investment, a plan for reform. London: Stationery Office, 2000.

3 Scottish Executive Health Department. Cancer scenarios: an aid to planning cancer services in Scotland in the next decade. Edinburgh: Scottish Executive Health Department, 2001.

4 Stewart S, Blue L. Improving outcomes in chronic heart failure. London: BMJ Publishing, 2001.

5 Coffey A, Atkinson P. Making sense of qualitative data: complementary research strategies. London: Sage, 1996.

6 Higginson I, Addington-Hall JM. Palliative care for non-cancer patients. Oxford: Oxford University Press, 2001.

7 Chavannes N. A palliative approach for COPD and heart failure. Eur J Palliat Care 2001;8:225-7.

8 Kurti LG, O'Dowd T. Dying of non-malignant diseases in general practice. J Palliat Care 1995;11:25-31.

9 Rideout E, Montemuro M. Hope, morale and adaptation in patients with chronic heart failure. J Adv Nurs 1986;11:429-38.

10 Lynn J. Serving patients who may die soon and their families. JAMA 2001;285:925-32.

11 Rogers AE, Addington-Hall JM, Abery AJ, McCoy ASM, Bulpitt C, Coats AJS, et al. Knowledge and communication difficulties for patients with chronic heart failure: qualitative study. BMJ 2000;321:605-7.

12 Lynn J. Learning to care for people with chronic illness facing the end of life. JAMA 2000;284:2508-11.

13 McCarthy M, Addington-Hall J, Ley M. Communication and choice in dying from heart disease. J $R$ Soc Med 1997;90:128-31.

14 The A-M, Hak T, Koeter G, Wal Gvd. Collusion in doctor-patient communication about imminent death: an ethnographic study. BMJ 2000;321:1376-81.

15 Girgis A, Sanson-Fisher RW. Breaking bad news: consensus guidelines for medical practitioners. J Clin Oncol 1995;13:2449-56.

16 Fallowfield L, Jenkins V, Farewell V, Saul J, Duffy A, Eves R. Efficacy of a cancer research UK communication skills training model for oncologists: a randomised, controlled trial. Lancet 2002;359:650-6.

(Accepted 27 August 2002)

\title{
Fish, meat, and risk of dementia: cohort study
}

\author{
Pascale Barberger-Gateau, Luc Letenneur, Valérie Deschamps, Karine Pérès, Jean-François \\ Dartigues, Serge Renaud
}

INSERM U330,

Université Victor

Segalen Bordeaux

2 , case $n^{\circ} 11,146$

rue Léo-Saignat,

33076 Bordeaux

Cedex, France

Pascale

Barberger-Gateau

senior lecturer

Luc Letenneur

researcher

Valérie Deschamps

research fellow

Karine Pérès

research fellow

Jean-François

Dartigues

professor

Serge Renaud

researcher

Correspondence to: P Barberger-Gateau Pascale.Barberger-

Gateau@isped.

u-bordeaux2.fr

BMJ 2002;325:932-3
The role of dietary fat in dementia arouses increasing interest. ${ }^{1}$ Fatty acids could be involved through several mechanisms, including atherosclerosis, thrombosis, and inflammation. ${ }^{2}$ We evaluated whether there is a relation between consumption of fish (rich in polyunsaturated fatty acids) or meat (rich in saturated fatty acids) and risk of dementia.

\section{Participants, methods, and results}

We obtained data from the PAQUID (Personnes Agées QUID) epidemiological study of cognitive and functional ageing (www.healthandage.net $/ \mathrm{html} / \mathrm{min} /$ paquid/entrance.htm). During the third wave of the study (1991-2) investigators visited 1674 people aged 68 and over without dementia and living at home in 75 parishes in southwestern France and recorded their frequency of consumption of meat and fish or seafood: daily, at least once a week (but not every day), from time to time (but not every week), never. Participants were followed up two, five, and seven years afterwards: 1416 $(84.6 \%)$ had at least one follow up visit. All the participants who had lost three points or more on the minimental state examination since a previous visit or were suspected of having dementia according to the criteria of the Diagnostic and Statistical Manual of Mental Disorders, third edition, revised (DSM-III-R) were visited by a neurologist to confirm the diagnosis.

We calculated the incidence of dementia per 100 person years. We used a Cox proportional hazards model with delayed entry to estimate the relative risk of dementia, taking into account age, sex, and education (at least the French primary school diploma "Certificat d'Etudes Primaires" versus less education ${ }^{3}$ ).

During the seven years of follow up 170 new cases of dementia occurred, including 135 cases of Alzheimer's disease. The table shows a significant trend between increasing consumption of fish or seafood and decreasing incidence of dementia ( $\mathrm{P}$ for trend=0.0091). Frequency of fish or seafood consumption was higher in the participants with higher education $(879 / 1051(83.6 \%)$ v 262/365 (71.8\%) consuming fish at least weekly; $\mathrm{P}<0.0001)$. Participants who ate fish or seafood at least once a week had a significantly lower risk of being diagnosed as having dementia in the seven subsequent years (age and sex adjusted hazard ratio $0.66,95 \%$ confidence interval 0.47 to $0.93)$. When we added education into the model the 
Incidence of dementia according to fish and meat consumption in elderly people in southwestern France

\begin{tabular}{|c|c|c|c|c|c|}
\hline & \multirow[b]{2}{*}{ Total No } & \multicolumn{2}{|r|}{ Dementia } & \multicolumn{2}{|c|}{ Alzheimer's disease } \\
\hline & & No of cases & $\begin{array}{c}\text { Incidence }(95 \% \mathrm{Cl}) \text { per } 100 \\
\text { person years }\end{array}$ & No of cases & $\begin{array}{c}\text { Incidence }(95 \% \mathrm{Cl}) \text { per } 100 \\
\text { person years }\end{array}$ \\
\hline \multicolumn{6}{|l|}{ Fish or seafood consumption: } \\
\hline Once a day & 19 & 1 & 1.00 (0.00 to 2.97$)$ & 1 & 1.00 (0.00 to 2.97$)$ \\
\hline At least once a week (but not every day) & 1122 & 124 & 2.05 (1.69 to 2.41$)$ & 99 & 1.64 (1.31 to 1.96$)$ \\
\hline From time to time (but not weekly) & 240 & 35 & 2.90 (1.94 to 3.87$)$ & 27 & 2.24 (1.39 to 3.08$)$ \\
\hline Never & 35 & 10 & 6.61 (2.51 to 10.70$)$ & 8 & 5.29 (1.62 to 8.95$)$ \\
\hline \multicolumn{6}{|l|}{ Meat consumption: } \\
\hline Once a day & 934 & 110 & $2.22(1.80$ to 2.63$)$ & 87 & 1.75 (1.38 to 2.12$)$ \\
\hline At least once a week (but not every day) & 450 & 53 & 2.21 (1.61 to 2.80$)$ & 44 & 1.83 (1.29 to 2.37$)$ \\
\hline From time to time (but not weekly) & 26 & 4 & $3.49(0.07$ to 6.90$)$ & 2 & $1.74(0.00$ to 4.16$)$ \\
\hline Never & 6 & 3 & 9.39 (0.00 to 20.01$)$ & 2 & $6.26(0.00$ to 14.93$)$ \\
\hline
\end{tabular}

hazard ratio was almost unchanged (0.73) but the $95 \%$ confidence interval (0.52 to 1.03$)$ slightly overlapped 1.00, indicating that the "protective" effect of weekly fish or seafood consumption was partly explained by higher education of regular consumers. Participants who ate fish or seafood at least once a week had a hazard ratio, adjusted for age and sex, of 0.69 for developing Alzheimer's disease in the seven following years, with borderline significance $(95 \%$ confidence interval 0.47 to 1.01 ). We found no significant association between meat consumption and risk of dementia $-\mathrm{P}$ for trend $=0.59$; age and sex adjusted hazard ratio for weekly consumers $0.56(0.26$ to 1.20$)$

\section{Comment}

Elderly people who eat fish or seafood at least once a week are at lower risk of developing dementia, including Alzheimer's disease. The Rotterdam study found similar results but had a much shorter follow up (mean 2.1 years). ${ }^{4}$ Given that the first consequences of dementia on everyday living can appear three years before diagnosis, ${ }^{5}$ poor dietary habits could be a consequence rather than a cause of cognitive decline in the Rotterdam participants.

In addition to providing vascular protection, the $n-3$ fatty acids contained in fish oils could reduce inflammation in the brain and may have a specific role in brain development and regeneration of nerve cells. ${ }^{2}$ Healthy dietary habits acquired in infancy could be associated with achievement of higher education. Highly educated people might also adhere more closely to dietary recommendations on fish consumption.

Contributors: PBG is co-manager of the PAOUID project and developed the concept of the study, contributed to the study design, statistical analyses, and interpretation of data, and wrote the paper. LL contributed to statistical analyses, interpretation of data, and revising the paper critically. VD contributed to the conception, data analysis, and critical review of the paper. KP contributed to data analysis and critical review of the paper. JFD is the other co-manager of the PAQUID project and contributed to the study design, interpretation of the data, and critical review of the paper. SR contributed to the conception, interpretation of the data, and critical review of the paper. All authors approved the final version. $\mathrm{PBG}$ is the guarantor.

Funding: Association pour la Recherche Médicale en Aquitaine (Bordeaux), Caisse Nationale d'Assurance Maladie des Travailleurs Salariés, Conseil Général de la Dordogne, Conseil Général de la Gironde, Conseil Régional d'Aquitaine, Fondation de France, France Alzheimer (Paris), Institut National de la Santé et de la Recherche Médicale, Mutuelle Générale de l'Education
Nationale, Mutualité Sociale Agricole, Novartis Pharma (France), SCOR Insurance (France).

Competing interests: None declared.

1 Grant WB. Dietary links to Alzheimer's disease: 1999 update. J Alzheimer Dis 1999;1:197-201.

2 Kalmijn S. Fatty acid intake and the risk of dementia and cognitive decline: a review of clinical and epidemiological studies. J Nutr Health Asing 2000:4:202-7.

3 Letenneur L, Gilleron V, Commenges D, Helmer C, Orgogozo JM, Dartigues JF. Are sex and educational level independent predictors of dementia and Alzheimer's disease? Incidence data from the PAQUII project. J Neurol Neurosurg Psychiatry 1999;66:177-83.

4 Kalmijn S, Launer LJ, Ott A, Witteman JCM, Hofman A, Breteler MMB. Dietary fat intake and the risk of incident dementia in the Rotterdam study. Ann Neurol 1997;42:776-82.

5 Barberger-Gateau P, Fabrigoule C, Helmer C, Rouch I, Dartigues JF Functional impairment in instrumental activities of daily living: an early clinical sign of dementia? J Am Geriatr Soc 1999;47:456-62.

(Accepted 7 May 2002)

\section{The burden of disease}

\section{Leading causes of death and premature death worldwide, 1990}

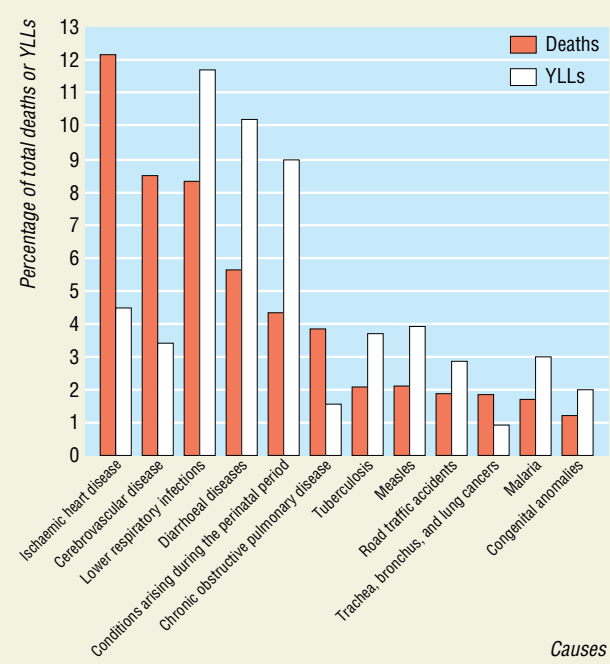

Reproduced with permission from Murray CJL, Lopez AD. The global burden of disease. Cambridge, MA: Harvard University Press, 1996

In contrast to crude data on deaths, the time based measure years of life lost (YLL) can identify the causes of premature death. This table shows the leading causes of death and of premature death, and gives many pointers for health policy. 